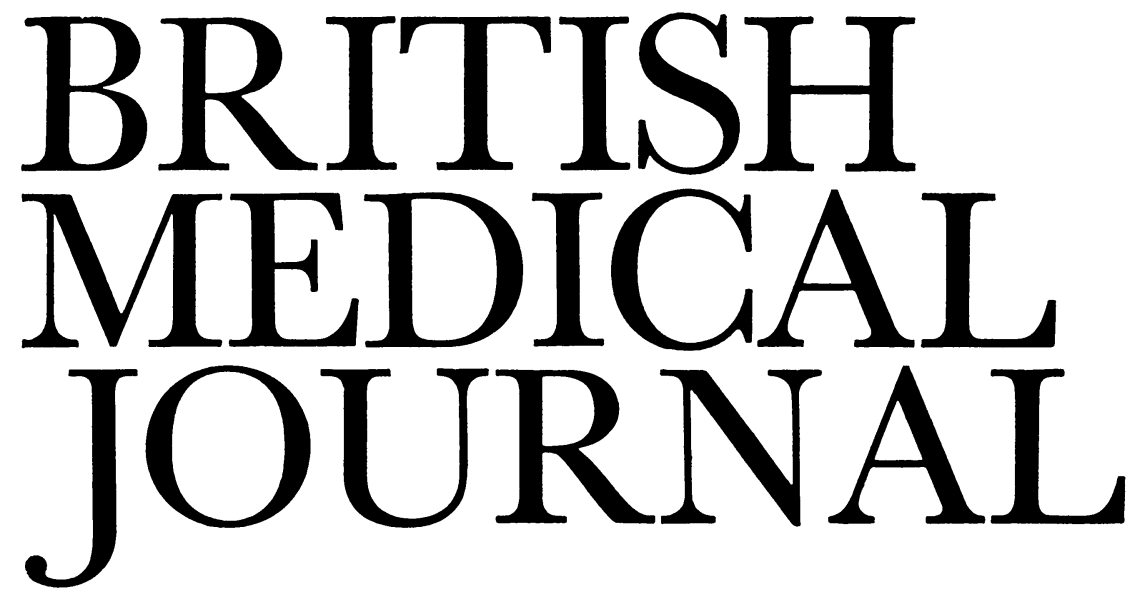

\title{
Transplantation of pancreas for insulin dependent diabetes
}

Most patients with juvenile onset diabetes can lead a nearly normal life with careful dietary control and injections of insulin, but some develop severe microangiopathic complications which may lead to blindness and renal failure. Little can be done for the progressive deterioration of vision, and, while dialysis and kidney transplantation may be offered to diabetics with renal failure, their increased susceptibility to infection and blood vessel disease as well as intolerance to corticosteroids make most forms of treatment hazardous. There are good reasons to believe that islet grafts functioning adequately would not only control the glucose metabolism but would also prevent the progression of microangiopathic lesions and in their early stages might even lead to some resolution. Relatively pure islets have been isolated in rats, and isologous grafts that cannot be rejected will prevent microangiopathy in diabetic animals. ${ }^{1}$ Transplantation of the islets in man is a very attractive prospect, but the technical factors have been insuperable. The human pancreas is more fibrotic than that of the rat, and pure undamaged human islets are extremely difficult to obtain in sufficient numbers for grafting. Moreover, isolated islets are more prone to rejection than are islets grafted in an intact pancreas. In the future, advances in immunosuppression, developments in islet extraction, and possibly culture of $\beta$ cells $^{2}$ may transform the therapeutic potential for diabetics, but for the present the best results of transplantation have been obtained using the intact pancreas, and particularly the body and tail of the pancreas vascularised by the splenic artery and vein.

The introduction of cyclosporin $\mathrm{A}$, a powerful immunosuppressant which can often be used without additional steroids, has stimulated further studies of pancreatic transplantation in man. ${ }^{3}$ The first graft of a pancreas in man was performed in the University of Minnesota in 1967 by Lillehei and Kelly. ${ }^{4}$ One of the troubles encountered was leakage of pancreatic juice causing abscess formation. Gliedman and colleagues introduced a technique of transplanting the hemipancreas and draining the pancreatic duct into the ureter. ${ }^{5}$ One of their patients treated with this method has long term function of the pancreas. In 1978 Dubernard and his colleagues $^{6}$ in Lyon introduced a new technique to prevent leakage of pancreatic juice: they injected neoprene into the pancreatic duct, resulting in atrophy and fibrosis of the exocrine secreting tissue but preservation of the islets, which became distorted and crowded together among the fibrous tissue.

A relatively straightforward surgical technique was therefore available together with immunosuppression without steroids; yet the results of pancreatic transplantation have continued to be extremely disappointing. ${ }^{7}$ There are several reasons for this. Firstly, primary vascular thrombosis has remained common; this has sometimes been attributed to kinking of the blood vessels but another probable factor is the sluggish blood flow in the large splenic vessels which normally supply and drain a much larger volume of tissue than just the body and tail of the pancreas. Introduction of the distal splenic arteriovenous shunt certainly increases the blood flow and may reduce this complication. ${ }^{8}$ Secondly, islet function may stop quite suddenly without there being good evidence of immunological rejection. For example, when the pancreas and kidney have been transplanted from the same donor only the pancreas may fail-indeed, in one case the pancreas and liver were taken from the same donor and the pancreas suddenly stopped functioning after a year, while the liver continues to function two years later without evidence of rejection. ${ }^{3}$ The kidney seems more susceptible to rejection than the pancreas, and pancreases transplanted together with kidneys from the same donor have usually fared better than those transplanted alone, possibly because rejection of the kidney may be detected more readily than rejection of the pancreas, so that appropriate treatment may be started before irreversible damage occurs.

The patient with our own longest functioning pancreatic transplant has returned to dialysis after three and a half years, since her kidney has failed from chronic rejection-but she still does not require insulin, having previously had a severe form of insulin dependent diabetes.

Leakage of pancreatic juice in the early operations was often attributed to the steroids used for immunosuppression, and with cyclosporin A now available two surgical groups have returned to more physiological drainage of pancreatic juice into a Roux loop of small intestine, ${ }^{910}$ a technique pioneered by Groth et al. ${ }^{11}$

Such techniques certainly preserve the architecture of the pancreas, both in studies on animals and in man, but sudden loss of $\beta$ cell function has occurred even when the technique has been satisfactory and there has been no evidence of 
rejection. In the University of Minnesota several patients have received pancreatic transplants from living related donors. ${ }^{12}$ In some cases the donor has given both the kidney and the pancreas. Removal of the hemipancreas is a more formidable operation than nephrectomy and the danger to the donor, not only from surgical complications but also from the possibility that the donor might develop diabetes, is a serious consideration that has deterred most other centres from this approach.

In two patients under the care of Sutherland et al in Minnesota islet cell function stopped abruptly in grafts that came from living donors (personal communication), in one case a sibling and the other an identical twin. In the former the histological appearances of the pancreas were normal apart from the absence of $\beta$ cells in the islets. In the latter there was intense mononuclear cellular infiltration confined to the islet tissue. Though conclusions on these observations must be tentative, these may be examples of the patient's own autoimmune disease that caused the diabetes affecting the grafted islets. Possibly this mechanism may have been responsible for the failure of other allografts but was not recognised as such owing to superimposed rejection. Appropriate immunosuppression might control autoimmune isletitis, and there are early pointers in this direction in patients with juvenile onset diabetes treated with cyclosporin A by Stiller and colleagues in London, Ontario. ${ }^{13}$

Despite flurries of optimism, the results of grafting of the pancreas still lag a long way behind those of kidney grafting. Even if this gap were abolished, moreover, there would be serious difficulties in obtaining enough pancreases for the very many patients afflicted with disabling progressive microangiopathy.

R Y CALNE

Professor of Surgery,

University of Cambridge,

Cambridge CB2 2QQ

${ }^{1}$ Gray BN, Watkins E Jr. Prevention of vascular complications of diabetes by pancreatic islet transplantation. Arch Surg 1976;111:254-7.

${ }^{2}$ Mandel TE, Georgiou H, Hoffman L, Carter WM, Koulmanda M, Dennington P. Proliferation of cultured and isografted fetal mouse pancreatic islets. Transplant Proc 1983;15:1362-5.

${ }^{3}$ Calne RY, Rolles $\mathrm{K}$, White DJG, et al. Cyclosporin $\mathrm{A}$ initially as the only immunosuppressant in 34 recipients of cadaveric organs: 32 kidneys, 2 pancreases, and 2 livers. Lancet 1979 ;ii :1033-6.

${ }^{4}$ Lillehei RC, Simmons RL, Najarian JS, et al. Pancreatico-duodenal allotransplantation: experimental and clinical experience. Ann Surg 1970;172:405-36.

${ }^{5}$ Gliedman ML, Gold M, Whittaker J, et al. Clinical segmental pancreatic transplantation with ureter-pancreatic duct anastomosis for exocrine drainage. Surgery 1970;74:171-80.

${ }^{6}$ Dubernard $M$, Traeger J, Neyra $P$, Touraine JL, Tranchant $D$, BlancBrunat N. A new method of preparation of segmental pancreatic grafts for transplantation: trials in dogs and in man. Surgery 1978; 84:633-9.

'Sutherland DER. Current status of pancreas transplantation: registry statistics and overview. Transplant Proc 1983;15:1303-7.

${ }^{8}$ Calne RY, McMaster P, Rolles K, Duffy TJ. Technical observations in segmental pancreas allografting: ubservations on pancreatic blood flow. Transplant Proc 1980;13, suppl 2:51-7.

${ }^{9}$ Calne RY, White DJG, Rolles K, Duffy TJ, Kass T. Renal and segmental pancreatic grafting with draining of exocrine secretion and initial continuous intravenous cyclosporin $\mathrm{A}$ in a patient with insulindependent diabetes and renal failure. $\mathrm{Br}$ Med $\mathcal{f} 1982 ; 285: 677-80$.

${ }^{10}$ Groth CG, Collste H, Lundgren G, et al. Successful outcome of segmental human pancreatic transplantation with enteric exocrine diversion after modifications in technique. Lancet 1982 ;ii :522-4.

${ }^{11}$ Groth CG, Lundgren G, Gunnarsson R, Härdstedt C, Östman J. Segmental pancreatic transplantation with special reference to the use of ileal exocrine diversion and to the hemodynamics of the graft. Transplant Proc 1980;12, suppl 2:62-7.

${ }^{12}$ Sutherland DER, Goetz FC, Elick BA, Najarian JS. Experience with 49 segmental pancreas transplants in 45 diabetic patients. Transplantation $1982 ; 34: 330-8$.

${ }^{13}$ Stiller CR, Laupacis A, Dupre J, et al. Cyclosporine for treatment of early type I diabetes: preliminary results. $N$ Engl f $\mathrm{Med} 1983 ; 308$ : 1226-7.

\section{Dementia: biological solution still a long way off}

The year 2000 will see a considerable demographic shift in the age structure of the world's population. In 1970 there were 291 million people over the age of 60 and, of these, 26 million were over 80 . The corresponding figures for the end of the century are expected to be in the region of $600 \mathrm{mil}-$ lion and 58 million respectively-with $20 \%$ or more of the over 80 s being demented. Of those affected at present, $55 \%$ suffer from senile dementia of Alzheimer type and 15\% from multi-infarct dementia. Some $22 \%$ suffer from mixed forms of dementia, and the remainder from various other, less common but nevertheless important and in some cases potentially reversible conditions. ${ }^{1}$

The demographic change will occur over a fairly short period, and adaptation is difficult in the face of rapid change. The need for increased residential accommodation will continue to grow, not only because of the continuing expansion in the numbers of over 80 s, the main recipients of such care, but also because of the increased survival of those in institutions. ${ }^{2}$ Bergman and colleagues have shown that intense community care in the form of day hospitals will not dispense with the need for beds. ${ }^{3}$ The problems will be further exacerbated by the changing expectations of the "young" elderly and their attendant relatives after many years' experience of Health Service care.

The main focus of the conference on research progress in dementia held at the Charing Cross Hospital Medical School in London in July was concerned with senile dementia of Alzheimer type. Its clinical features include the slow development of failure of memory and intellect, loss of interest, aimlessness, blunted emotion, and lack of insight. The condition often starts with depression and is accompanied by wide ranging cognitive deficits, which include dysphasia, dyscalculia, visuospatial defects, and difficulties in abstract thinking and orientation. This widespread disorder of cortical functioning is reflected in the pathological changes with lesions not only in the cerebral cortical tissue but also in the subcortical nuclei whose cell bodies have axonal projections to the cortex.

Interest in the neurological aspects of senile dementia of Alzheimer type began with research implicating the cholinergic system, ${ }^{4}$ whose neurones arise in the basal nucleus. Marker enzymes of this system, choline acetyltransferase and acetylcholinesterase, were shown to have reduced activity, the extent correlating well with the severity of the dementia. Furthermore, the neuronal content of these nuclei was shown to be reduced and neurofibrillary tangles were identified. Since then other subcortical nuclei and their transmitter systems have been brought into the picture, including the locus ceruleus, which is noradrenergic; the raphe nucleus, which is serotoninergic; and the substantia nigra, which is dopaminergic. The precise relation of changes in some of these systems to senile dementia of Alzheimer type still remains uncertain, however, since these nuclei play some part in the process of aging in patients who do not show evidence of dementia. Nevertheless, in addition to the cholinergic system the noradrenergic system seems likely to be implicated: indices of malfunctioning in this system correlate with the degree of dementia and with pathological indices of dementia such as the senile plaque count.

Why these four systems should be affected specifically in senile dementia of Alzheimer type we do not know. They 